\title{
Iconografía sobre la salud en el Obispado de Trujillo (1782-1785)
}

Artículos originales: HISTORIA

Recibido: 05/09/2020

Aprobado: 16/10/2020

Publicado: 05/02/2021
Emma Patricia Victorio Cánovas Universidad Nacional Mayor de San Marcos evictorioc@unmsm.edu.pe

Luis César Ramírez León

Universidad Nacional Mayor de San Marcos Iramirezl@unmsm.edu.pe

\begin{abstract}
RESUMEN
En esta nota se pretende visualizar la problemática de la salud en el virreinato peruano en función de la información gráfica que brinda el repertorio de acuarelas encargadas por el obispo Martínez Compañón durante la visita a su jurisdicción en el norte del Perú, entre 1782 a 1785. La intención es también analizar las referidas representaciones en las acuarelas para entender de modo general los estragos que causaban las enfermedades y las epidemias en la población, además de las soluciones médicas oficiales y populares que se empleaban en ese tiempo; y asimismo, comprender el esfuerzo de los artistas populares anónimos para la representación gráfica de estos males.
\end{abstract}

Palabras clave: salud; enfermedades; epidemias; acuarelas; obispado de Trujillo; Martínez Compañón.

\section{Health iconography in the Bishopric of Trujillo (1782-1785)}

\begin{abstract}
This note aims to visualize the health problems in the Peruvian viceroyalty based on the graphic information provided by the repertoire of watercolors commissioned by Bishop Martínez Compañón during his visit to his jurisdiction in northern Peru, between 1782 and 1785 . The intention is also to analyze the referred representations in the watercolors to understand in a general way the ravages caused by diseases and epidemics in the population, in addition to the official and popular medical solutions that were used at that time; and also, to understand the effort of these anonymous popular artists for the graphic representation of these evils.
\end{abstract}

KEYwords: Health; diseases; epidemics; watercolors; bishopric of Trujillo; Martínez Compañón. 


\section{Introducción}

E n la administración del virreinato peruano se debe tener en cuenta la conformación de la «república de españoles» y la «república de indios», además de un sector social amplio conformado por los africanos, y dentro de los españoles e indios también se debe tener en cuenta el nivel socio-económico. Los primeros por ser la parte dominante, tuvieron mayores privilegios también en el campo de la salud y sufrieron menos ante el embate de las enfermedades y epidemias; mientras los indígenas y esclavos, fueron los que más sufrieron las enfermedades infectocontagiosas, acentuadas también por las condiciones de explotación, hacinamiento y desnutrición a que estaban sometidos ${ }^{1}$.

En las grandes ciudades como Lima se fundaron hospitales, como es el caso del Hospital Real (1545) que luego pasó a ser el Hospital Real de San Andrés, ${ }^{2}$ el primero establecido de manera oficial para atender a los españoles sin recursos económicos ${ }^{3}$ y el Hospital para naturales de Santa Ana (1549), ambos ubicados alrededor de la Plaza de Santa Ana, en los Barrios Altos; posteriormente se fundó el de San Bartolomé, para negros esclavos y libertos (1684), además del leprosorio de San Lázaro (1563), entre los más importantes de la capital del virreinato. Estos establecimientos de salud estuvieron regentados por órdenes religiosas dedicadas a la tarea de cuidar a los enfermos y su edificación fue emplazada en zonas elevadas por razones de higiene, para aislarlos y evitar el contagio de la población ${ }^{4} \mathrm{y}$, a la vez, facilitar el abastecimiento de agua y alimentos para subsistir. En Cusco, gracias a Juan Rodríguez Villalobos se fundó muy temprano el hospital San Lázaro, que en 1549 pasó a manos de los francisca-

1 Es una problemática que se inicia desde los tiempos de la conquista, consúltese la tesis de Antuñano Colpaher, Rosario Del Pilar (2014). Salubridad y epidemias en la ciudad de Lima 1535 - 1590.

2 Sobre la fecha de su fundación, la información no es precisa, Iza y Salaverry señalan que su origen se remonta a «1552 cuando Francisco de Molina atendía en su casa en el Callejón de Santo Domingo a enfermos que carecían de recursos" (Iza y Salaverry 2000: s/n).

3 Aunque originalmente el hospital atendía tanto a espańoles como a naturales.

4 Como se lee en la Ordenanza 122 de 1573 «Cuando se fundare o poblare alguna ciudad, villa o lugar, se pongan los hospitales para pobres y enfermos de enfermedades que no sean contagiosos en lugares levantados y partes que ningún viento dañoso pasando por hospitales vaya a herir en las poblaciones». (Recopilación de las Leyes de Indias (1680). Libro I. Título IV. De los hospitales y cofradías. Ley I. Que se funden hospitales en todos los pueblos de españoles e indios). nos. Asimismo, para atender a españoles y mestizos se estableció — en terrenos a espaldas de la catedral — un hospital bajo la advocación de Nuestra Señora de la Piedad (1548); y para la atención de los indios se levantó el Hospital de Naturales en 1556. En este contexto, Trujillo no podía ser la excepción, en 1551 se fundó al lado de la ermita — hoy iglesia — de Santa Ana, el Hospital Belén, con el nombre de Hospital de Santiago, para atender las necesidades sanitarias de la población y enfrentar epidemias que la afectaban.

Sin embargo, fuera de las grandes ciudades y en especial en el mundo rural el mantenimiento de la salud corrió a cargo de las mismas personas o por medio de curanderos tradicionales y médicos con conocimientos más bien prácticos. Ejemplos de ello han sido ilustrados durante el siglo XVIII en imágenes de acuarelas por pintores anónimos, que formaron parte del proyecto administrativo del Obispo Baltazar Martínez Compañón y Bujanda, que se encuentran reunidas bajo el título Trujillo del Perú. Obra enviada al rey de Espańa, Carlos IV, aunque iniciada para su antecesor Carlos III, que proyectaba incluir en una posible historia de su obispado.

De origen español, Martínez Compañón (n. Cabredo 1737 - m. Bogotá 1797) ${ }^{5}$ fue un hombre ilustrado cuyo interés estuvo centrado, en primer lugar, al conocimiento de la diócesis de su jurisdicción que, por sus dimensiones de entones «era un verdadero monstruo geográfico» (Macera 1997: 21) con la intención de garantizar una administración adecuada, y mejorar las condiciones de vida de una población disímil, conformada por un alto porcentaje de indios y de negros.

Con la aspiración de conocer el extenso territorio de su jurisdicción —que abarcaba los departamentos de Piura, Lambayeque, La Libertad, Cajamarca, Chachapoyas, San Martín y Loreto-, hizo un viaje para recorrerlo de palmo a palmo. Durante su «Visita pastoral», que se realizó entre 1782 y 1785, el obispo estuvo acompańado por un grupo de artistas anónimos y sin formación académica, lo que explica el aspecto particular de las láminas que manifiestan desconocimiento de las proporciones, la anatomía y la perspectiva

5 El artículo no pretende analizar la extensa biografía de este ilustre hombre del siglo XVIII, pero vale la pena anotar que «Por Cédula Real de 25 de febrero de 1778, se le promovió al Obispado de Trujillo, siendo consagrado como tal en Lima en 25 de marzo de 1779. Ejercería el pontificado en Trujillo por espacio de once ańos, años prolíficos en realizaciones y trabajos..." (Real Academia de la Historia). 


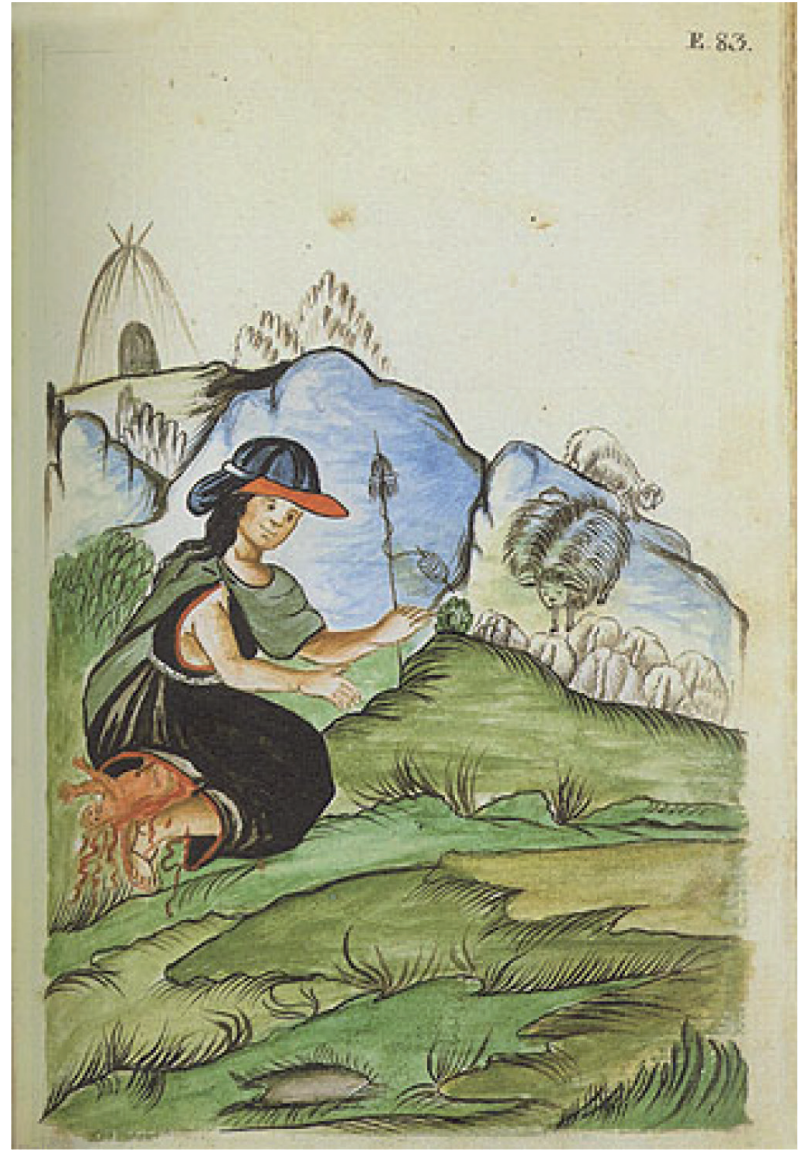

Fig. 1. "Yndia pastora pariendo», estampa 83, Vol. II.

así como dificultades en la representación de los rostros. Las imágenes son descriptivas y han sido realizadas sobre papel mediante la técnica de la acuarela, pigmento diluido en agua, que fue la favorita de las expediciones científicas, propias del siglo XVIII, pues permite plasmar el apunte directo del natural, agiliza el trabajo, facilita la mezcla de colores y seca de manera rápida.

El conjunto de acuarelas revela el interés científico de Martínez Compañón expresado en este registro monumental. A la vez, se trata de un documento que muestra una iconografía ${ }^{6}$ de primer orden que expo-

6 Según el Diccionario de la Lengua Española (2001) el término ico-

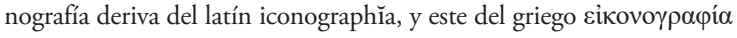
significando «imagen» y «descripción», su función consiste en la descripción de imágenes, retratos, cuadros, estatuas o monumentos, especialmente de la antigüedad (Diccionario de la Lengua Espańola, vigésima segunda edición). Panofsky en su libro Estudios sobre Iconología de 1939 (ha sido traducido a varios idiomas y reeditado muchas veces, la edición consultada es de 1980) define la iconografía como la rama historia del arte que estudia el contenido de la obra de arte. Los niveles pre-iconografico e iconográfico se refieren a la identificación de las imágenes por lo que son en sí mismas y los temas respectivamente; el tercer nivel, llamado iconológico, se refiere al contenido, es decir, la ne diversos aspectos de la región a su cargo, tanto el territorio como la naturaleza, los habitantes y las costumbres, cuenta con más de mil cuatrocientas láminas, aunque probablemente algunas no fueran terminadas sino hasta 1790. En este proyecto, Martínez Compañón se anticipó a la Expedición Botánica del Nuevo Reino de Granada (Colombia) realizada por José Celestino Mutis que se inició en 1783.

Martínez Compañón se preocupó de su Obispado y levantó planos y mapas de Trujillo y las demás ciudades y pueblos de su jurisdicción con afán modernizador. Justamente en el plano de la ciudad norteña se aprecia solamente el hospital de los Bethlemitas y el Hospital de Mujeres, lo cual evidencia el problema crucial en la asistencia médica de la población. ${ }^{7}$ En efecto, sobre el tema de la salud y el auxilio a los que tenían acceso los naturales en la región, hay imágenes reveladoras de cómo la mujer indígena da a luz en el campo, sola, sin contar con la asistencia de persona alguna. En la figura 1 se observa a la izquierda de la composición, una mujer pastora sonriente que hila de manera despreocupada con una pushka (o rueca tradicional) dispuesta en sentido vertical. La mujer está de rodillas, de perfil con el cuerpo hacia la derecha. Viste el característico anaco negro (especie de túnica) que ciñe a su cintura con un chumpi (faja), y una lliclla (manta) que cae desde sus hombros, envuelve su espalda y parte de su pecho, se trata de prendas de origen prehispánico. Cubre su cabeza con una montera. La hora del parto le llegó mientras realizaba su labor, la cual suspende, y el bebé sale de entre sus piernas hacia atrás, se distinguen la sangre y el cordón umbilical alrededor de su pequeño cuerpo. En el fondo se observa el paisaje campestre, un rebaño de ovejas y la choza, que seguro representa su hogar, alejada en la cima de una montańa.

Asimismo, en otra acuarela también se observa cómo un hombre es atendido por un odontólogo empírico en la extracción de una muela, y seguramente de modo directo, sin la aplicación de alguna anestesia usando una tenaza similar al fórceps para el procedimiento (Fig. 2).

Lo curioso de la imagen es que, quien parece ser el paciente no es un indio como lo titula la acuarela, sino un español o criollo, y quien funge de dentista

interpretación de las alegorías y la trama literaria contenida en ellas, en el presente artículo no se pretende llegar a este nivel interpretativo.

7 Puede consultarse el «Plano de la ciudad de Trujillo», fol. 12r, Vol. I, en Trujillo del Perú. 


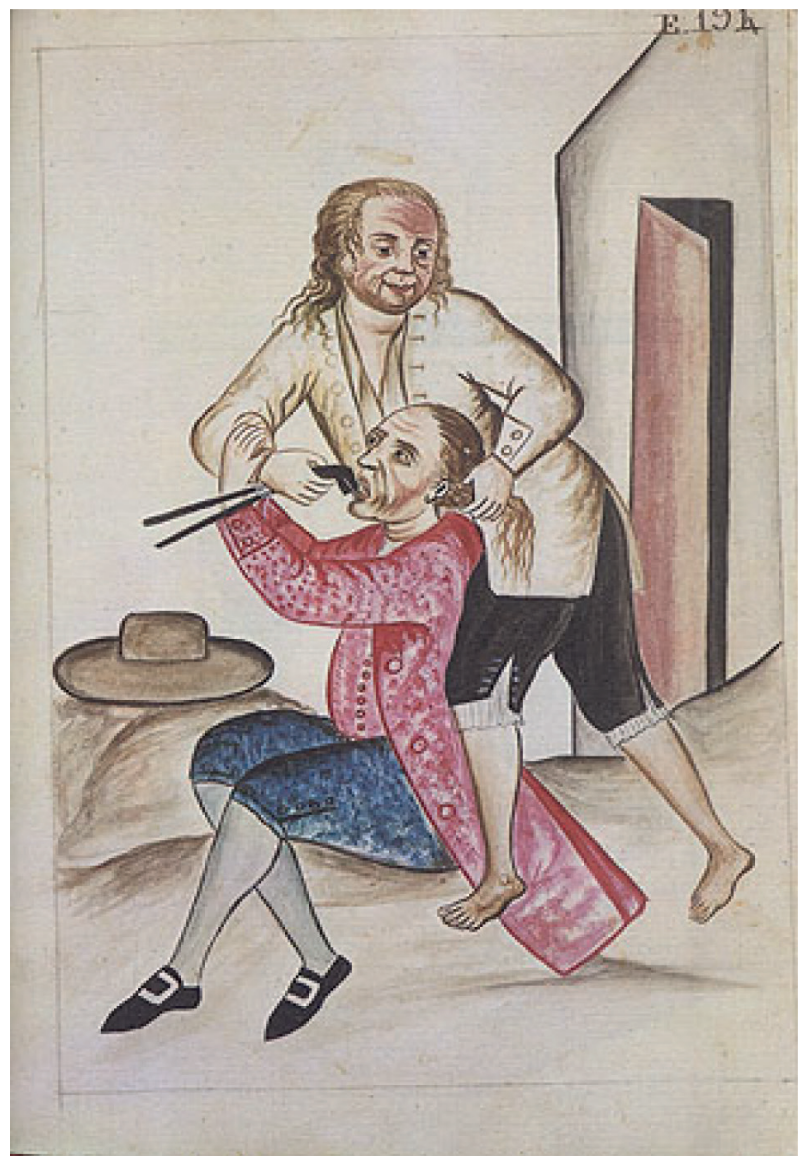

Fig. 2. "Yndio sacándose las muelas», estampa 194, Vol. II, Trujillo del Perú.

es un indio que sujeta del cabello al primero e introduce la tenaza en su boca. Se deduce que es un indio por el aspecto facial, algo más rústico, y por la calidad de su vestimenta, pues el "dentista» luce algo desalińado y está descalzo, lo cual denota su extrema pobreza, mientras que el paciente está elegantemente ataviado, lleva levita roja, pantalón ceńido hasta las rodillas, medias de seda y zapatos negros con hebilla. La escena se desarrolla en el interior de una habitación y ocupa el centro de la composición. El paciente está sentado en el piso hacia la izquierda, sobre el piso de tierra, con las piernas cruzadas adelante y apoya su espalda sobre el cuerpo del dentista que está de pie a su lado. La impericia del artista es evidente en el tratamiento del espacio pues ambos personajes parecen flotar.

Es seguro que en tiempos virreinales era común la práctica de ciertos procedimientos médicos habituales propios de la medicina práctica, uno de ellos era el de «sangrar» al paciente, lo cual se podía ejercer en los mismos hogares o en el "consultorio médico»

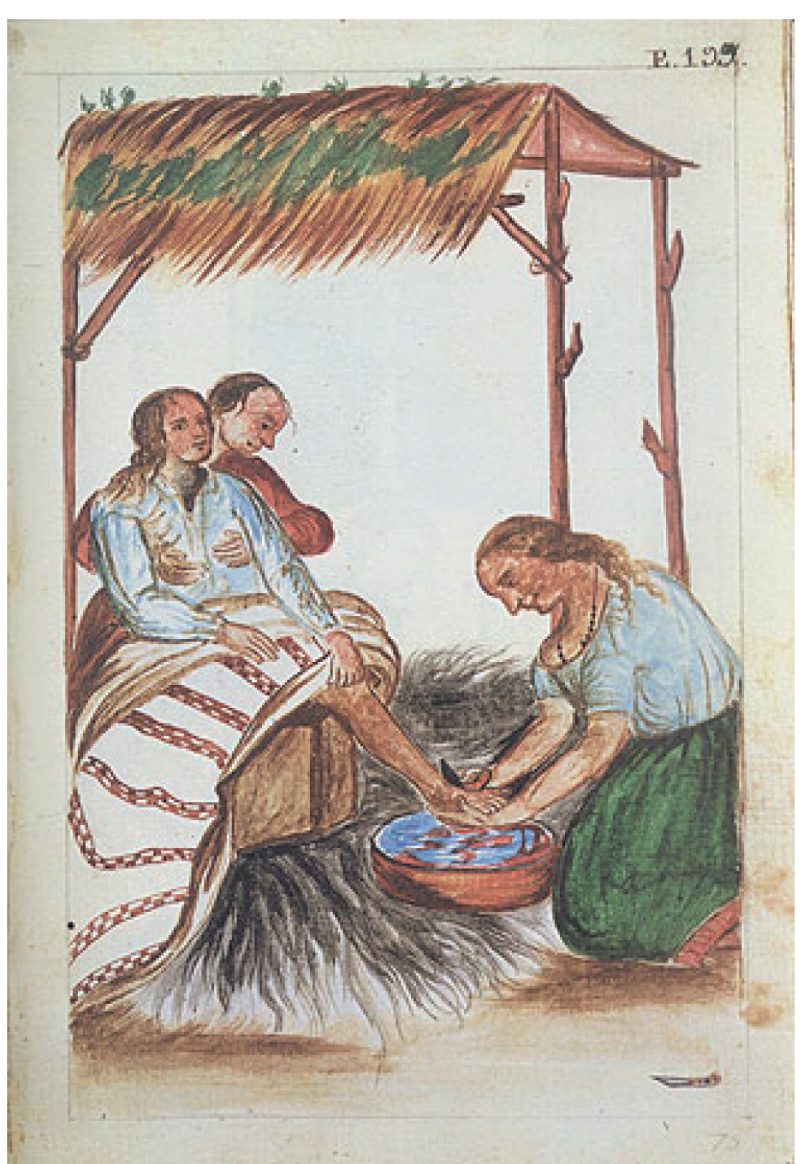

Fig. 3. «Yndio sangrándose», estampa 199, Vol. ॥

del empírico, tal como se aprecia en la Fig. 3. Llama la atención en esta acuarela ofrecida por Martínez Compañón, que quien ejerce la función de médico es una mujer, lo que destaca que el oficio de sangrador era practicado tanto por hombres como por mujeres.

Se trata de una curandera, quien aplica unos cortes en el pie del paciente, también mujer, la cual es sostenida por un varón, que puede ser el esposo. Este procedimiento del sangrado todavía se usa en lugares apartados de la serranía para aliviar los males de la presión arterial alta o en ciertos estados propios de la mujer en relación al embarazo o la menopausia. La escena se desarrolla debajo de una estructura precaria de troncos con cubierta de paja que también cae sobre el piso. La curandera está a la derecha, de rodillas, viste una falda verde con ornamentación en el borde inferior y una blusa que deja ver sus brazos; mientras que su paciente, que está a la izquierda sentada sobre un taburete, viste una chaqueta celeste y tiene una manta blanca, con listas de colores de indudable confección andina, que la cubre desde la cintura y deja ver su pantorrilla desnuda. 


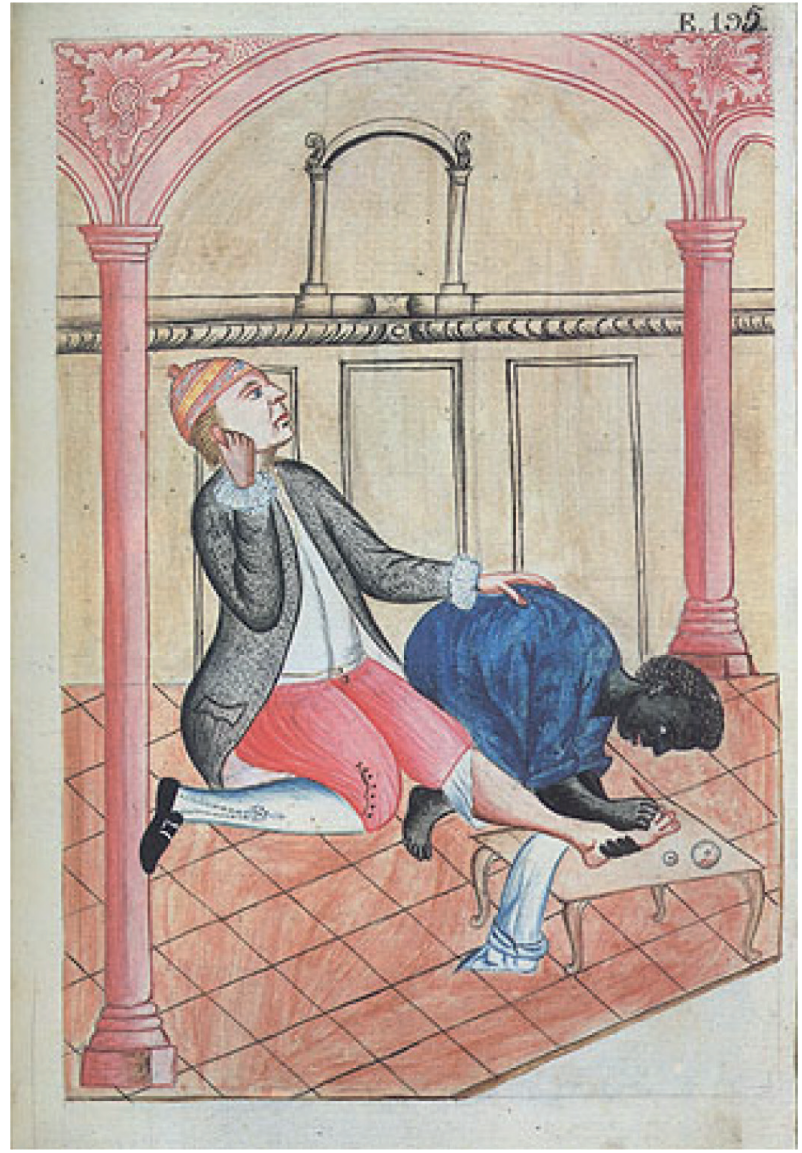

Fig. 4. «Negro sacando piques», estampa 195, Vol. II.

Otros males, propios del ambiente de insalubridad o de la condición paupérrima de los pobladores de la región, es el ataque de los parásitos en la piel, como es el caso de los piques (Fig. 4).

El pique, conocido también como nigua, en quechua, es un tipo de pulga que anida en la piel, mayormente en los pies, en especial entre los dedos, produciendo escozor y llagas dolorosas que pueden llegar a infectarse si no son retirados a tiempo; por ello en la figura citada se aprecia a un paciente español que es atendido por un negro, probablemente su esclavo. El primero está vestido correctamente a la usanza del siglo XVIII con chaqueta, camisa, pantalón ceñido hasta las rodillas, medias de seda y zapatos, pero también lleva un chullo ${ }^{8}$ en la cabeza, que oculta su cabello. El negro, vestido de azul, sujeta el pie izquierdo de su amo que está apoyado sobre una mesa baja, para extraer los bichos. Al parecer

8 El chullo es un gorro común en el área andina, tejido a palitos — técnica de origen europeo- que tiene una punta en la parte superior y apéndices que cubren las orejas.

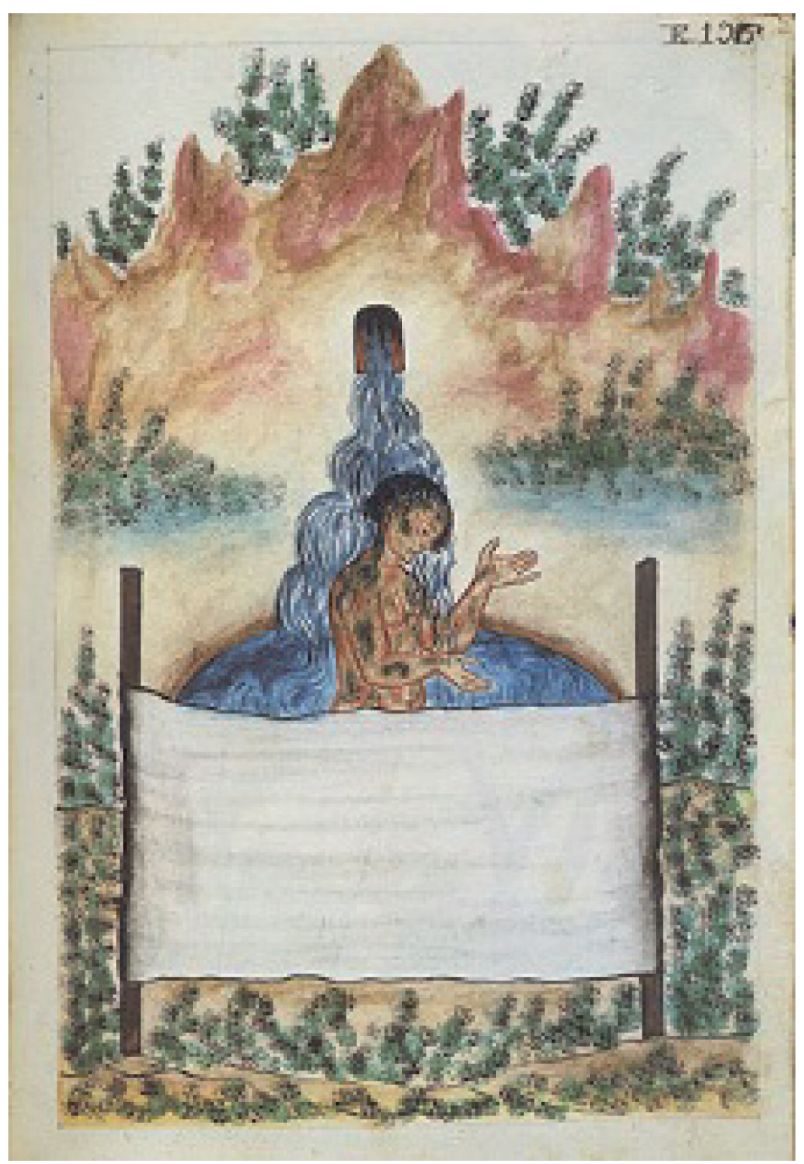

Fig. 5. «Leprosa bañándose», estampa 196, Vol. II, Trujillo del Perú.

recién se inicia el mal, pues en el otro pie lleva el zapato. El ambiente arquitectónico es el de una casona acomodada, pues la escena parece desarrollarse en el patio interior en el que destacan los elementos arquitectónicos como las columnas, los arcos y los vanos; el piso de losetas. Téngase en cuenta que si el mal atacaba a una persona de esta condición social debe haber sido por falta de higiene, pues los más propensos eran los indios y negros quienes trabajaban descalzos o con sandalias precarias, llamadas ojotas, en ambientes sucios y húmedos por la presencia de las excreciones del ganado.

Respecto a las epidemias se tienen aquellas que los espańoles trajeron con la conquista y aquellas que son locales o endémicas. De las primeras, una de las más antiguas es la lepra que, aunque no fue masiva, su presencia fue significativa, tanto que en Lima se destinó el hospital San Lázaro para tratar esta enfermedad, y en otras ciudades como Trujillo su presencia fue notoria, tal como la ilustra una de las acuarelas de Martínez Compañón (Fig. 5). 


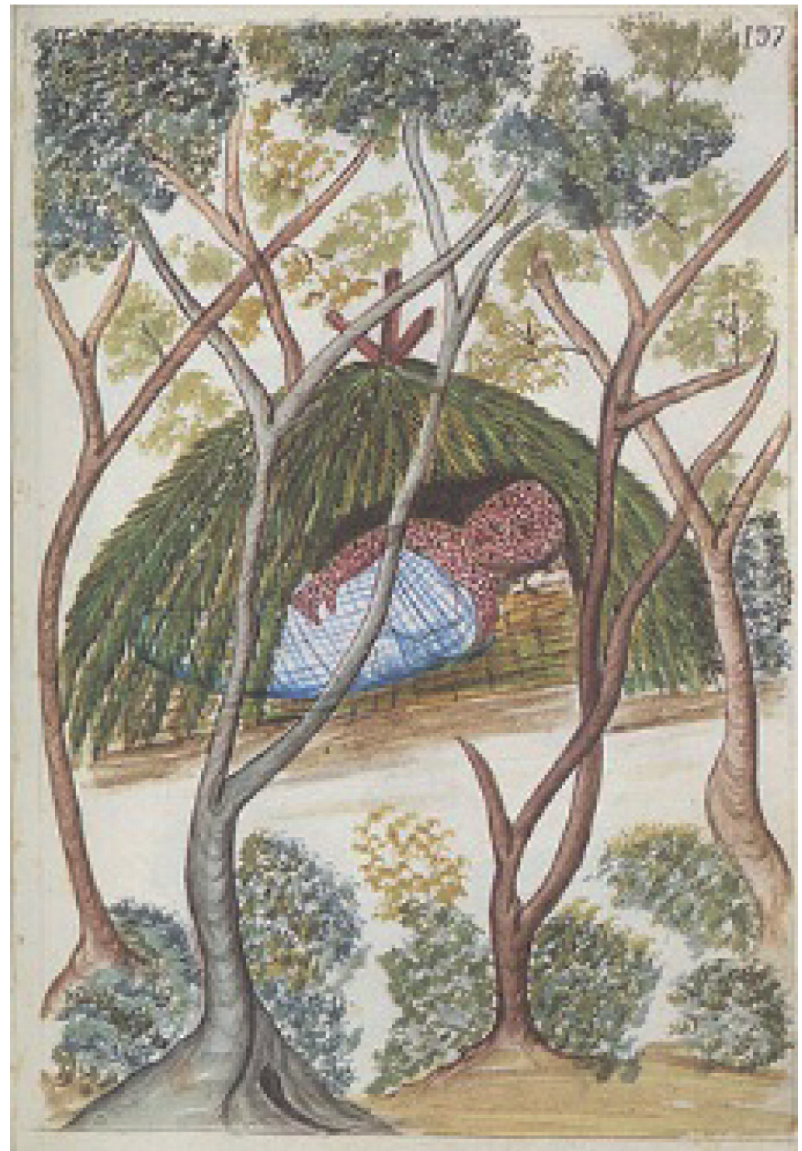

Fig. 6. «Yndio con virgüelas», estampa 197, Vol. II.

En la imagen se aprecia una mujer bañándose al aire libre en un pequeño estanque, con el agua que brota de un puquio o manantial, y llega desde un cerro que está al fondo. Ella está de pie y desnuda, en posición de tres cuartos hacia la derecha. Su desnudez está protegida por una tela blanca extendida en primer plano y sostenida por dos parantes, que solo deja ver su torso cubierto de llagas.

Otras enfermedades epidémicas fueron la influenza o gripe; el tifus o tabardillo transmitido por pulgas de las ratas o piojos; la viruela y el sarampión, conocidas desde la llegada de los españoles, entre cuyos síntomas se cuentan las fiebres altas. En la información gráfica de Martínez Compañón es posible observar los estragos de la viruela como lo demuestra la Fig. 6.

La ilustración referida muestra al enfermo desnudo, envuelto con una manta y cubierto de erupciones en el rostro y parte del cuerpo visible, está recostado en el piso, sobre un petate. Se encuentra totalmente aislado en el campo, tan solo resguardado por una choza de ramas. La soledad del enfermo demuestra el

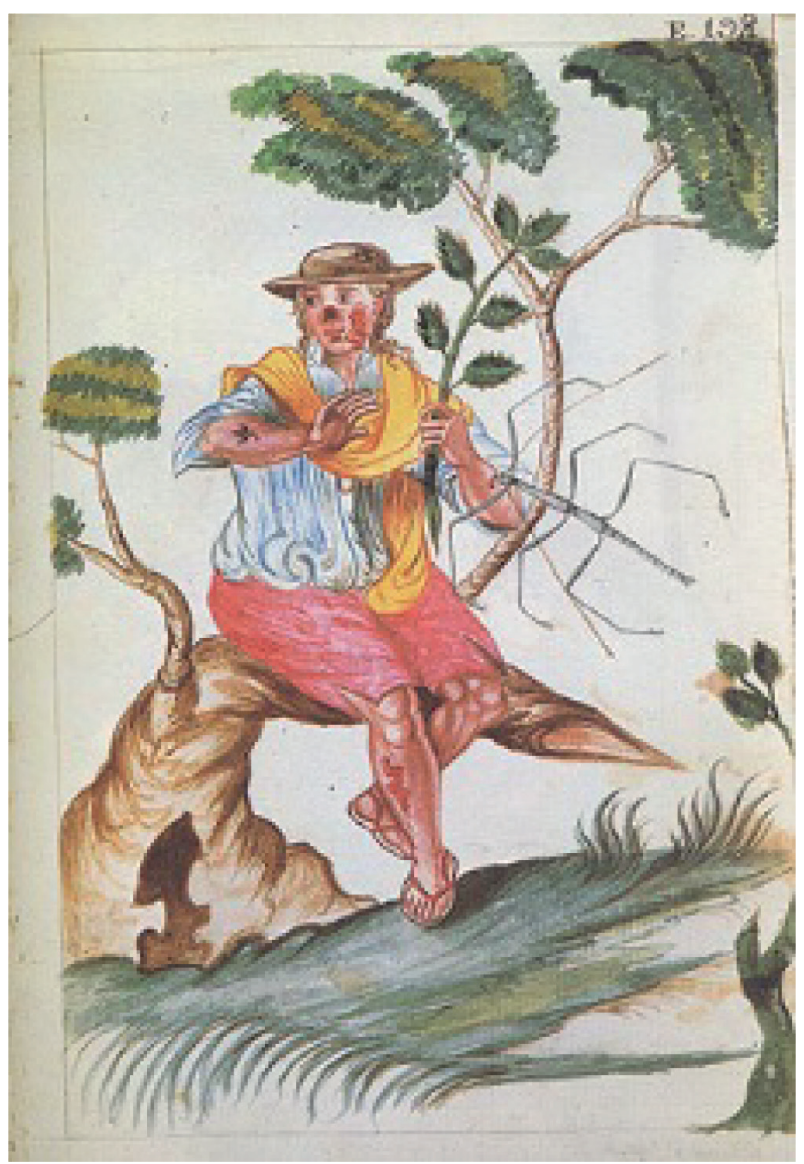

Fig. 7. «Mestizo picado de Vta», estampa 198, Vol. Il, Trujillo del Perú.

temor que se tenía entonces por la viruela, enfermedad sumamente contagiosa y mortal, que dejaba cicatrices permanentes en la piel de quienes lograban sobrevivir a ella. La choza se encuentra detrás de una arboleda que remarca el aislamiento del paciente, a quien probablemente le espera una muerte inminente.

Dentro de las plagas locales u originarias del Perú se anota la terrible uta, conocida como una enfermedad de las leishmaniasis, o grupo de enfermedades parasitarias zoonóticas, transmitida por insectos dípteros hematófagos. Estas enfermedades comprometen la piel, mucosas y vísceras. Por lo general se da en los lugares cálidos, como en la costa o las quebradas que descienden a la selva o a la costa, ataca a los labios y la nariz, desfigurando a las personas para toda la vida si es que no les causa la muerte, lo cual queda plenamente ilustrado en la Fig. 7, en la que se muestra un mestizo con dicha enfermedad.

El hombre ha sido representado al aire libre, vestido de manera sencilla, con pantalón a la rodilla y camisa, tiene una bufanda que cruza su pecho, som- 


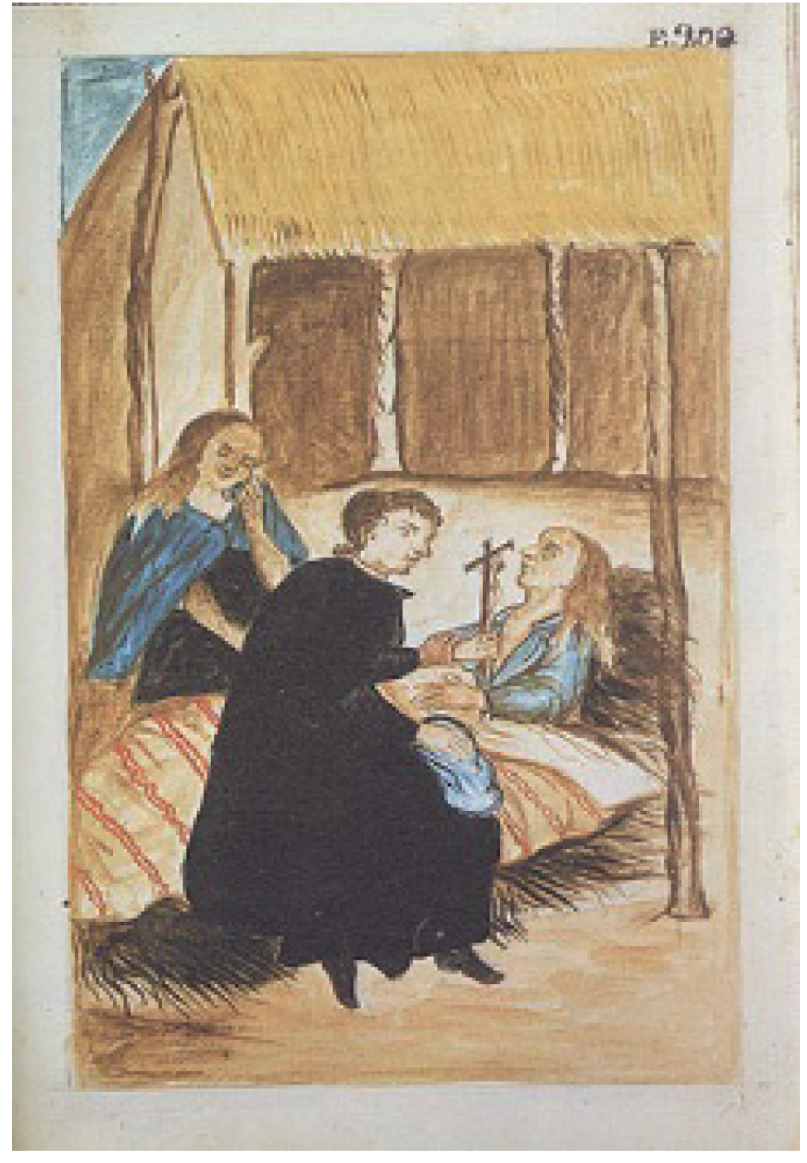

Fig. 8. “Yndio en agonía», estampa 200, Vol II, Trujillo del Perú.

brero y sandalias. Está sentado en el tronco de un árbol que se dobla hacia la derecha. Se aprecia que la enfermedad no solo ha afectado su rostro, pues ha perdido prácticamente toda la nariz, también tiene llagas en la mejilla izquierda, y en el antebrazo derecho y la pierna del mismo lado. Es interesante observar que, con afán documental, el insecto causante de la uta se ha incluido sobrepuesto al hombre, y para destacarlo está dibujado de mayor tamaño al lado derecho según el espectador.

De todos esos males de origen endémico, tuvo una fama especial el paludismo o malaria, cuya transmisión también es producida por insectos. El mal se presenta con la aparición de una crisis febril muy alta que puede alcanzar los $41^{\circ} \mathrm{C}$, la cual es intermitente y se da sobre todo por las noches. Destaca por haber atacado a miembros prominentes de la república de espańoles en tierras peruanas y americanas, y en especial, por haberse aplicado para su curación los conocimientos de remedios nativos como la corteza del árbol de la quina, que en la gran obra del ilustre obispo Martínez Compañón aparece nominado de diversos modos, como "cascarilla», "quinaquina» y "quinas». El árbol de la quina posteriormente se clasificó como la Cinchona officinalis (Rubiaceae) que alude a una supuesta curación de la condesa de Chinchón, esposa del virrey del Perú quien gobernó entre 1629 y 1639. Dadas las bondades del árbol de la quina no solo ha sido incluido en el escudo nacional del Perú, sino que también forma parte del patrimonio natural de la nación.

En fin, lo que interesa de la planta es la corteza, con la cual se produce la quinina, un alcaloide con propiedades antipiréticas, antipalúdicas y analgésicas. Por supuesto, que los habitantes del antiguo Perú usaban el producto natural, originario de la selva lluviosa, para controlar la malaria, y realmente fueron los jesuitas quienes la propalaron hacia mediados del siglo XVII. ${ }^{9}$ Sin embargo, no fue sino hasta 1820 cuando la quinina fue extraída químicamente de la corteza.

A ello se añaden otras enfermedades similares, también transmitidas por insectos, como la fiebre amarilla o la verruga peruana, u otro tipo de males como la tuberculosis y el cáncer, entre otros. Todas estas enfermedades se enfrentaban con los remedios obtenidos del conocimiento de las flora local, así en el repertorio de plantas medicinales del álbum de Martínez Compañón están ilustradas la "cathahua», empleada para combatir la tifoidea y también el cáncer, y la "jagua», buena para combatir la tuberculosis. En todos los casos, cuando se trata de la representación de la flora medicinal, hay una preocupación tanto por la imagen del árbol con sus detalles como por el minucioso tratamiento de las hojas o los frutos, de tal manera que quede claro cómo es cada uno para evitar confusiones.

Como se ha mencionado antes, sin duda, la enfermedad que mayores atenciones mereció fue el paludismo y por eso, por lo menos, por las acciones de prevención en la jurisdicción de Trujillo, la obra del obispo Martínez de Compañón muestra el cultivo de la cascarilla (o la quina) como algo elemental, pues según un cuadro se aprecia que se promovió su siembra, aunque se cultivaba solo en Trujillo y en Huamachuco.

Este es el panorama de los males epidémicos que fueron recurrentes en el virreinato peruano. A estas calamidades se suman males menores que también causaban la muerte; sin embargo, no hay compara-

9 El médico italiano Sebastiano Bado escribió hacia 1650: «Esta corteza ha resultado ser más preciosa para la humanidad que todo el oro y plata que los Españoles hayan sacado del Perú» (Álvarez 2013: 214). 
ción cuando la vida se extingue debido a una epidemia, por lo terrible que resulta la pérdida masiva de vidas, por ello es preferible «la buena muerte», asistida por los familiares y el protocolo del párroco.

La conmovedora escena que muestra la Fig. 8 se refiere al momento en el cual el sacerdote administra el último de los sacramentos, la extremaunción, a un hombre postrado en su lecho de muerte, semi-cubierto con una manta tejida de características locales (blanca con listas rojas) que sujeta un crucifijo y mira la imagen de Cristo. El sacerdote, con el viático, está en primer plano, sentado al lado izquierdo del lecho. Más atrás, completa la escena la esposa del hombre, que acongojada, levanta la mano hacia su cara en actitud doliente. Todo se desarrolla en un ambiente precario que corresponde al interior de una choza.

En suma, lo que se advierte en la iconografía de las acuarelas encargadas por el obispo Martínez Compañón con respecto al tema de la salud, es la precariedad en el cuidado de la población rural, donde las enfermedades comunes eran atendidas empíricamente y las epidemias, que fueron recurrentes, fueron enfrentadas con métodos propios de la herbolaria y la curandería, y entre cuyos remedios destaca especialmente el árbol de la quina con sus variedades.

No obstante el Obispo tuvo intenciones de administrar su jurisdicción con la modernización de las luces, según el modelo europeo, aplicarla en la realidad fue muy difícil, por lo que su residencia en el Perú le significó recorrer su jurisdicción para un mejor conocimiento de sus problemas así como de sus riquezas materiales y culturales. Eso sí, tuvo la confianza en la gente de su entorno y en especial de los maestros pintores. Es decir, supo comprender a los artistas anónimos que trabajaron para él, pues a pesar de carecer de un aprendizaje académico lograron representar y expresar de manera precisa la idea o el tema que pretendían comunicar, y en la mayoría de los casos, no exentos de mostrar la cruda realidad respecto a las carencias para el tratamiento de los males que aquejaban la salud de la población, y en algunos casos aunque suene paradójico lo hicieron con una nota de gracia o humor pintoresco ya sea consciente o inconscientemente, como es el caso del enorme insecto en primer plano causante de la uta o en la concepción desequilibrada del espacio arquitectónico por la falta del conocimiento de la perspectiva.

\section{Bibliografia}

Álvarezz Alonso, José (2013). «El árbol de la calentura». En Boletin del Instituto Nacional de Salud. $\mathrm{N}^{\circ}$ 9-10 (pp. 214-215).

Antuñano Colpaher, Rosario Del Pilar (2014). Salubridad y epidemias en la ciudad de lima 1535-1590. Tesis para optar el título profesional de Licenciado en Historia, UNMSM. Disponible en: http://cybertesis. unmsm.edu.pe/handle/cybertesis/3828

García Bryce, José (1981). "La arquitectura en el virreinato y la república». En: Historia del Perú. Procesos e instituciones, tomo X. Lima, Editorial Juan Mejía Baca (pp. 11-166).

Iza, Agustín y Salaverry, Oswaldo (2000). «El Hospital Real de San Andrés». Anales de la Facultad de Medicina. UNMSM. Vol. 61, No 3. Disponible en: http://sisbib. unmsm.edu.pe/bvrevistas/anales/v61_n3/Hosp_Real_ San_And.htm

Macera, Pablo; Jiménez Borja, Arturo; Franke, Irma (1997). Trujillo del Perú. Baltazar Jaime Martínez Compañón. Acuarelas. Lima: Fundación del Banco Continental. Disponible en: https://fundacionbbva. pe/wp-content/uploads/2016/04/libro_000049.pdf

Macera, Pablo (1997). «El tiempo del obispo Martínez Companón.» En: Macera, Pablo; Jiménez Borja, Arturo; Franke, Irma (1997) Trujillo del Perú. Baltazar Jaime Martínez Compañón. Acuarelas. Lima: Fundación del Banco Continental. Disponible en: https://fundacionbbva.pe/wp-content/uploads/2016/04/libro_000049.pdf

Martínez Compañón, Baltazar Jaime. Trujillo del Perú, Vols. I-IX. Disponible en: http://www.cervantesvirtual.com/portal/patrimonio/catalogo.shtml

Panofsky, Erwin (1980). Estudios sobre iconología. Madrid: Alianza Universidad.

Real Academia de la Historia. "Baltazar Jaime Martínez Companón y Bujanda»: http://dbe.rah.es/ biografias/13509/baltasar-jaime-martinez-companony-bujanda

Salaverry, Oswaldo (2008). «Hospitales coloniales de Lima. Galería fotográfica». En: Revista Peruana de Medicina Experimental y Salud Pública. Vol. 25 №3: 345-347.

SÁNCHEZ-SALDAÑA, Leonardo et al. (2004). «LEISHMANIASIS». En: Dermatología Peruana. Vol. $14, \mathrm{~N}^{\circ} 822$. 